Full length article

\title{
Unveiling barriers to sustainable public procurement in emerging economies: Evidence from a leading sustainable supply chain initiative in
}

\section{Latin America}

\author{
Diego Delmonico ${ }^{\mathrm{a}}$, Charbel Jose Chiappetta Jabbour ${ }^{\mathrm{b}, *}$, Susana Carla Farias Pereira ${ }^{\mathrm{c}}$, \\ Ana Beatriz Lopes de Sousa Jabbour ${ }^{\mathrm{b}}$, Douglas William Scott Renwick ${ }^{\mathrm{d}}$, \\ Antônio Márcio Tavares Thomé
}

a UNESP - The Sao Paulo State University, Production Engineering Department, Sao Paulo, Brazil

${ }^{\mathrm{b}}$ Montpellier Business School, Montpellier Research in Management, 2300 Avenue des Moulins, 34080 Montpellier Cedex 4, France

${ }^{c}$ FGV - EAESP, Department of Production \& Operations Management, Fundação Getulio Vargas, São Paulo, Brazil

${ }^{\mathrm{d}}$ Nottingham Business School, Nottingham Trent University, Nottingham, UK

e Industrial Engineering Department, Pontifical Catholic University of Rio de Janeiro, Rua Marquês de São Vicente, 225 sala: $952 L$ - 22453-900, Rio de Janeiro, Brazil

\section{A R T I C L E I N F O}

\section{Keywords:}

Sustainable operations

Sustainable public procurement

Sustainable supply chain

Sustainable purchasing

Latin America

\begin{abstract}
A B S T R A C T
In light of the Theory of Ecological Modernisation, this is the first work to explore the organisational barriers affecting one of the most significant sustainable public procurement initiatives in Latin America: the Brazilian Environmental Agenda for Public Operations Management (the 'A3P Programme'). This article explores the barriers to sustainable procurement in a Brazilian context, inspired by the work of Brammer and Walker (2011). Based on the results of a survey of programme managers, our first recommendation is to group the barriers to sustainable procurement into five categories: organisational culture, motivation, economic uncertainty, market, and operations. Amongst these, it was found that organisational culture stands out as a particular barrier to sustainable public procurement. This work also highlights Ecological Modernisation Theory as a useful tool for understanding why variables related to cost and budget are not barriers to implementing sustainable public procurement initiatives. Consequently, the main implication of this study is that government should consider cultural change management when developing sustainability management initiatives.
\end{abstract}

\section{Introduction}

Based on the principles of Ecological Modernisation Theory (Zhu et al., 2013) as applied to sustainable operations (Sarkis et al., 2011; Walker et al., 2014), the objective of this work is to understand the main barriers to sustainable public procurement in Brazil. The barriers to sustainable procurement in the public sector proposed by Brammer and Walker (2011) were explored in a Brazilian context and original results were obtained. Although this research is inspired by Brammer and Walker (2011), its exploratory approach also owes much to the work of Oliveira and Santos (2015). According to Oliveira and Santos (2015), Brazil's sustainable public purchasing is less structured than in other countries, and has faced challenges on legal, operational and cultural grounds.

Sustainable procurement is considered a key practice of sustainable supply chains in emerging economies (Mathivathanan et al., 2018;
Mani et al., 2016; Kusi-Sarpong et al., 2015). The Brazilian public sector accounts for $15 \%$ of the country's gross domestic product (GDP), through its acquisition of goods and services. This is equivalent to more than US $\$ 100$ billion (Ministry of Planning, Budget and Management, 2012) and follows the worldwide trend of significant national spending on public procurement. Brazil is amongst the world's largest ten economies, and is a member of important international groups such as the BRICS group and Mercosur. Despite the country's large economy, it has received little attention in studies addressing sustainability and issues related to the supply chain (e.g. Fahimnia et al., 2015). There are, for example, works on sustainable public procurement in countries such as China (Zhu et al., 2013), India (Agarchand and Laishram, 2017), Saudi Arabia (Islam et al., 2017), South Africa (Mashele and Chuchu, 2018) and Malaysia (Mcmurray et al., 2013). The existing research tends to examine particular-mostly developed-countries, such as the UK, Sweden, the USA and Germany (Brammer and Walker, 2011;

\footnotetext{
* Corresponding author.

E-mail addresses: diegodelmonico@fclar.unesp.br (D. Delmonico), c.chiappettajabbour@montpellier-bs.com (C.J.C. Jabbour), susana.pereira@fgv.br (S.C.F. Pereira), a.sousa-jabbour@montpellier.com.br (A.B.L.de Sousa Jabbour), douglas.renwick@ntu.ac.uk (D.W.S. Renwick), mt@puc-rio.br (A.M.T. Thomé).
} 
Table 1

Sample of research articles in sustainable purchasing.

\begin{tabular}{|c|c|c|}
\hline Research & Summary & $\begin{array}{l}\text { Research Methodology (Literature Review, } \\
\text { Qualitative or Quantitative) }\end{array}$ \\
\hline $\begin{array}{l}\text { Brammer and Walker } \\
\text { (2011) }\end{array}$ & $\begin{array}{l}\text { The authors reveal that sustainable procurement practices are evident in public sector procurement, } \\
\text { but vary across regions. In addition, the authors highlight the main facilitators of and barriers to } \\
\text { sustainable procurement. }\end{array}$ & Quantitative (Survey) \\
\hline $\begin{array}{l}\text { Dawson and Probert } \\
\text { (2007) }\end{array}$ & $\begin{array}{l}\text { The authors propose that public bodies can close the recycling loop by using sustainable } \\
\text { procurement initiatives to facilitate the inclusion of green waste compost in contract specifications }\end{array}$ & Quantitative (Survey) \\
\hline Ho et al. (2010) & $\begin{array}{l}\text { With a focus on Asia, the authors show that government's involvement in green procurement is } \\
\text { found to directly determine its overall effectiveness. They show that public leadership on green } \\
\text { procurement has advanced green procurement in the private sector. }\end{array}$ & Qualitative (Case Study) \\
\hline Mcmurray et al. (2013) & $\begin{array}{l}\text { Based on a survey of Malaysian private and public managers, it was found that lack of awareness } \\
\text { posed the most significant barrier to sustainable procurement implementation, regardless of } \\
\text { organisation or sector. }\end{array}$ & Quantitative (Survey) \\
\hline Miemczyk et al. (2012) & $\begin{array}{l}\text { This paper provides a structured literature review of sustainability in purchasing and supply } \\
\text { management. }\end{array}$ & Literature Review \\
\hline Nijaki and Worrel (2012) & $\begin{array}{l}\text { The authors show how local entities, such as cities and counties, can use environmentally preferable } \\
\text { purchasing to boost the local green economy. }\end{array}$ & Qualitative (Case Study) \\
\hline
\end{tabular}

Roman, 2017; Palm and Backman, 2017), with a scarcity of studies in a Brazilian context. Additionally, the public sector has been re-shaped by contemporary developments in procurement, which require further analysis (Panayiotou et al., 2004).

As a consequence of new environmental laws and governance systems (Jabbour et al., 2014), Brazil has been working to steer the public sector towards sustainability. In recent decades there have been significant government efforts to expand sustainability initiatives, such as the development of the Environmental Agenda in Public Administration (A3P) programme. This is a Ministry of the Environment (MMA) programme whose objective is to encourage the adoption of environmental practices within public agencies, as well as gathering information on existing environmental practices. This is the largest public sector sustainable procurement programme in Latin America.

Despite the considerable increase in sustainable public procurement in Brazil in recent years, there are concerns that few public purchases made in the country (Oliveira and Santos, 2014) incorporate any sustainability criteria. For this reason, it is important to understand the barriers that may be preventing A3P from achieving the maximum success possible.

The study of barriers is appropriate in contexts where the adoption of transformative measures for solving important issues faces challenges (Luthra et al., 2016). The literature (Walker et al., 2012) indicates that studies on this subject in developing countries are extremely relevant because of the social impact they can generate.

In order to achieve the research objective, the following five steps were taken: (i) a review of the literature on barriers to sustainable procurement was conducted, in order to identify useful variables; (ii) these variables were then tested against the opinions of specialists as to their formal suitability and content, in order to design the research questionnaire; (iii) a preliminary survey of potentially suitable organisations was carried out; (iv) Survey Monkey was used to deliver the research instrument developed for collecting the data; (v) the data were analysed using correlation analysis and factor analysis with the help of IBM's SPSS software, which measured the relationships between the variables and categorised them into factor groups.

The main contributions of this research are: (i) a survey of the main barriers to sustainable public procurement in Brazil, filling a gap in the literature and presenting new perspectives on the subject; (ii) a survey of possible relationships between variables, with the potential to increase understanding of the phenomenon as well as providing a basis for theoretical studies; (iii) a categorisation of the barriers identified, enabling the visualisation of the structure of problems involving sustainable public procurement. This research is unique when compared with previous studies in sustainable purchasing (for example, Ramayah et al., 2010) and aims to address the demand for more research on sustainability in the supply chains of emerging economies (KusiSarpong and Sarkis, 2017). It also answers early calls for additional research in sustainable infrastructure (Thomé et al., 2016) and sustainable urban infrastructure development (Ferrer et al., 2018), which are largely led by public procurement in emerging economies.

The Theory of Ecological Modernisation was adopted as it has previously been used to explain government-led initiatives to push forward green management practices in emerging economies (Sarkis et al., 2011; Yee et al., 2013; Zhu et al., 2015). The methodological approach chosen - exploratory statistics—-was deemed appropriate due to the lack of knowledge regarding the Brazilian Environmental Agenda for Public Operations Management (the 'A3P Programme').

Following this introduction, Section 2 presents the theoretical basis for sustainable public procurement. Section 3 discusses methodology, focusing on sample definition, data collection procedures and the research instrument. The fourth section presents the research results in the form of descriptive statistics, correlation analysis, factor analysis and the Kruskal-Wallis test. Section 5 analyses the results in the light of the literature on sustainable public procurement. The final section of the article considers the work's limitations.

\section{Theoretical background}

The fields of sustainable operations management (Dubey et al., 2017) and industrial sustainability (Smart et al., 2017; Dubey et al., 2016) have increasingly attracted the attention of researchers, and include topics such as sustainable supply chain management (Seuring and Müller, 2008; Gunasekaran and Irani, 2014), of which sustainable public procurement forms part. This concept is normally understood as the application of sustainable procurement to public sector purchasing processes (Oruezabala and Rico, 2012), and is defined by the search for sustainable development by way of the procurement process (Walker and Brammer, 2012). Sustainable procurement increases complexity along with the variety of issues that have influenced developments in contemporary procurement (Gunasekaran et al., 2009; Jin and Yu, 2015), particularly in the public procurement sphere (Panayiotou et al., 2004). An overview of some of the key studies on sustainable procurement, and the research methodology used in these, is presented in Table 1.

The discussion on sustainable public procurement began with an analysis of the relationships between the public and private sectors. As a consequence of this initial study, a number of investigations were conducted. Van Hoof and Lyon (2013) consider the government's use of the procurement process to encourage sustainable practices in private companies. Blay-Palmer et al. (2013), Preuss (2007, 2009), Preuss et al. 2011 discuss how local governments have used the procurement 
process to develop sustainability, while local economic development is dealt with by Nijaki and Worrel (2012) and Mercado et al. (2016). Lastly, adherence to government recommendations on sustainable public procurement by players from different spheres of government is considered by Thomson and Jackson (2007).

As far as existing research into the barriers to sustainable public procurement is concerned, qualitative studies on the public hiring process were identified (Testa et al., 2016), as were assessments of initiatives on the subject (Morgan, 2008). Critical factors and conditions for making sustainable public purchases are discussed by Ageron et al. (2012). Zhu et al. (2013) also present an investigation of the relationship between motivators and practices in sustainable public procurement.

Among works which directly address the barriers to public procurement, the identification of psychological barriers to the adoption of sustainable purchases is of particular note (Preuss and Walker, 2011), as are the assessment of opportunities and barriers in Malaysian organisations (Mcmurray et al., 2013), and a comparative assessment of barriers and facilitators in an international context (Brammer and Walker, 2011). The main conclusions drawn from these studies show that acquisition costs and budgetary constraints are critical barriers to the advancement of sustainable public procurement initiatives (Zhu et al., 2013; Brammer and Walker, 2011; Walker and Brammer, 2009), and that support, attitude, organisational culture and leadership style are also factors that hinder sustainable public procurement (Roman, 2017; Islam et al., 2017; Brammer and Walker, 2011).

The discussion on barriers to sustainable public procurement is still evolving and there is no definite consensus. Taking this into consideration, this article aims to explore the subject through the lens of Ecological Modernisation Theory, which aligns with the Brazilian A3P programme, and is used to explain the government's environmental initiatives for reconciling economic and environmental development (Sarkis et al., 2011).

Based on the gaps identified in the literature (Table 1) regarding the lack of works on sustainable public procurement in Latin America-and particularly in terms of the A3P programme-empirical exploratory research was conducted as follows.

\section{Methods}

This work uses a quantitative approach in the form of a self-administered survey questionnaire, which is a widely used technique across management research (Walker and Brammer, 2009, 2012; Walker and Preuss, 2008; Mcmurray et al., 2013).

\subsection{Sample definition and data collection procedures}

Organisations that are part of the A3P government programme were selected for this research. Among its various guidelines, this programme includes the insertion of social, environmental and economic criteria into the acquisition of goods, hiring of services and work in the public sector (MMA, 2016a).

The Brazilian Ministry of the Environment (MMA) provided contact information, including the telephone numbers and email addresses of organisations participating in the A3P programme. A total of 189 public organisations were identified as being part of the programme.

Elements of Dillman's Total Design Method (1991) were used, as described by Hoddinott and Bass (1986). However, the contact information provided by the MMA was subject to certain difficulties, such as changes in telephone numbers and e-mail addresses. The organisations were first contacted by telephone, at which point they were invited to take part in the research and to supply a valid e-mail address to which the questionnaire could be sent. After this initial phase, contact was made with the objective of increasing the rate of return of the research.

A total of 54 valid replies were ultimately obtained, giving a response rate of $28.5 \%$. This rate can be considered a satisfactory response rate for this type of survey research (Malhotra and Grover, 1998; Frohlich, 2002), and compares favourably with similar survey work reported in sustainability research (e.g., 8\% response rate from Bhadauria et al., 2014; 21\% from Chu et al., 2017). Although we began with an exhaustive list of public bodies, several telephone contacts were no longer available, or had changed. Additionally, in many organisations it was not possible to identify either those responsible or their new e-mail addresses, making it impossible to include them in the research. Due to these limitations, analysis was initiated as soon as the response number reached the minimum number suitable for an exploratory analysis.

The number of valid responses exceeded 50, the minimum number acceptable according to the literature on exploratory factor analysis (De Winter et al., 2009; Hair et al., 2005). The objective of exploratory factor analysis is to identify the underlying relationships between variables (Hair et al., 2005; Mulaik, 1987), offering the possibility of a theoretical interpretation of these correlations. Therefore, the number of replies was suitable for the objective of this analysis.

\subsection{Preparation of the research instrument}

The questionnaire was prepared using the variables proposed by Walker and Brammer (2009) because of their acceptance and consolidated position across the literature. In order to minimise problems of interpretation, translation and adaptation relating to the barriers proposed by Walker and Brammer (2009), face and content validation were performed, in which the drafted and translated statements were sent to a group of four researchers to be checked for clarity, meaning, and interpretation of the statements. The statements were then adapted to include three questions about the participating organisations: the particular agency involved, the position of the respondent and the amount of time the agency had been part of the A3P programme.

The finalised questionnaire was disseminated via Survey Monkey, with questions structured on a five-point Likert scale, in which five options were given: 5 - "I fully agree"; 4 - "I agree"; 3 - "I neither agree nor disagree"; 2 - "I disagree" and 1 - "I completely disagree".

After the data had been collected, the results were analysed using the SPSS 21.0 statistical software. The first step was to prepare a descriptive analysis of the data, calculating the mean, mode, median, and standard deviation. Second, Spearman's rank correlation analysis was carried out in order to measure the degree of correlation between two variables, a suitable method for data that does not follow a normal distribution (Frugolli, 2015). The relevant significance value resulting from the analysis were then collected. Finally, exploratory factor analysis was carried out in order to investigate patterns among variables (R-type), a method suitable for an exploratory approach. As this work utilised a scale inspired by Walker and Brammer (2009), translated from English to Portuguese, exploratory analysis proved suitable.

The factor analysis was also accompanied by the KMO test, which indicates the adequacy of the sample size for analysis purposes in relation to the number of variables involved. In order to support the factor analysis, the following were also used: commonality measures, which represent the total variance that an original variable shares with all others; eigenvalue analysis, which calculates the amount of variance explained by a factor; and Cronbach's alpha analysis, which is the reliability measure used in factor analysis, and whose lower acceptability values range from 0.6 to 0.7 (Hair et al., 2005).

The questions included about the organisations participating in the research made it possible to carry out the Kruskal-Wallis test (e.g. Ruxton and Beauchamp, 2008), which is used to detect patterns in distribution sets. The variables were organised according to Table 2, inspired by Walker and Brammer (2009). 
Table 2

Control variables for the Kruskal-Wallis Test.

\begin{tabular}{|c|c|c|}
\hline Category & Variable & Criterion \\
\hline \multirow[t]{3}{*}{ Nature of the organisation } & Org 1 & Organisational sphere ( 1 - federal organisations; 2 - sub-national organisations) \\
\hline & Org 2 & Level at which the agency operates ( 1 - federal; 2 - state and regional; 3 - local) \\
\hline & Org 3 & Administrative classification ( 1 - direct administration; 2 - indirect administration) \\
\hline \multirow[t]{2}{*}{ Position of the respondent } & Pos 1 & Hierarchical level ( 1 - planning; 2 - operational; 3 -n/a) \\
\hline & Pos 2 & Relationship of role to environmental management ( 1 - direct focus; $2-$ marginal focus) \\
\hline Time/Period of participation in A3P & Tem 1 & Time since A3P was adopted ( $1-$ not adopted; $2-4$ years or less; $3-5$ years or more) \\
\hline
\end{tabular}

\section{Results}

\subsection{Descriptive analysis}

Table 3 shows that the highest average values were calculated for variables V5, "the disarticulation between spheres in the public sector in planning, organising, directing and controlling sustainable procurement", with an average of 3.98 , and V6, "the existence of conflicts between procurement process priorities (for example: lowest price vs. quality and sustainability)" with an average of 3.83. This indicates that these are the main barriers to sustainable public procurement from the point of view of the respondents.

The lowest values were for the variables V11, "the perception that more sustainable products are associated with lower quality (for example: the use of recycled material, reuse, etc.)", and V20, "the perception that investing in environmental purchases may threaten/generate competition with regard to adopting other initiatives and social projects", which implies that these variables are not barriers to sustainable public procurement initiatives in Brazil, according to the perspective of the respondents.

\subsection{Correlation analysis}

Two-tailed significance tests were used to estimate the $p$ value. Although the results show a number of significant relationships between the variables, the loadings of the significant correlations are relatively low, with values between 0.34 and 0.48 , which indicates weak to moderate correlation (Table 4).

The highest significant $(\mathrm{p}<0.01)$ loading is between variable V8, "the lack of organisational culture/attitude for supporting and strengthening sustainable procurement" and V9, "the lack of a longterm vision in the organisation that is compatible with investment in sustainability", with a total loading of 0.683 . Another significant correlation is between variables V13, "the lack of government policies that encourage sustainable public procurement" and V17, "the lack of incentives and pressure to adopt sustainable public procurement initiatives", with a correlation coefficient of 0.575 .

The variables V3, "the lack of resources and organisational structure for making sustainable procurement feasible (for example: human resources, information systems)" and V6, "the existence of conflicts between procurement process priorities (for example: lowest price vs. quality and sustainability)" had the highest number of significant correlations $(\mathrm{p}<0.01)$.

\subsection{Factor analysis}

The sample was first subjected to adequacy tests for factor analysis, and measures to assess the validity of the sample were derived, such as the calculation of commonalities (Table 5). In the analysed data, there are both high (v7) and low (v18) values of commonality, but most have values between 0.5 and 0.75 , which is considered high by the literature (Jung and Lee, 2011).

The Kaiser-Meyer-Olkin (KMO) sample suitability test gave a result of 0.665, and Bartlett's sphericity test has a significance of 0.0001. Both results indicate the adequacy of the sample (e.g., Lau, 2011; Sangle,
2010). The analysis of the internal consistency of the sample, Cronbach's alpha test, returned a value of 0.8453 , indicating good sample consistency for factor analysis (Mcmurray et al., 2013).

To combine the variables into factor groups, a sufficient number of factors were considered for an eigenvalue equal to or less than 1 . This resulted in a total of 5 factors, which were classified as: a) Aspects of Organisational Culture; b) Motivational Aspects; c) Aspects of Economic Uncertainty; d) Market Aspects; and e) Operational Aspects.

The results of the factor analysis can be seen in Table 6 .

Factor 1 is represented by a cluster of 7 variables, listed in Table 7 . Organisational culture, as defined by Schein (1983), can be understood as the basic assumptions a particular group has developed for dealing with certain problems relating to external adaptation or internal integration. Accordingly, the variables in Factor 1 share characteristics related to culture and behaviour, including the structure assumed by the organisation.

Table 8 shows the composition of the second factor - the motivational aspects. According to Hwang et al. (2013), motivation can be considered to be the level of willingness to perform activities and tasks voluntarily when so requested. Motivation is perceived to be a common point among the variables that compose this factor, which involve policies, pressure, incentives, guidelines and the positive perception associated with sustainable public procurement.

This factor was the only one that included a variable with a significant negative value, variable V11: "the perception that more sustainable products are associated with lower quality (for example: the use of recycled material, reuse, etc.)". One interpretation for this negative value within the context of Factor 2 would be that the greater the perception that sustainable products have poorer quality, the greater the need for incentives to develop sustainable procurement.

Table 9 shows the composition of Factor 3, which groups the variables related to aspects of an economic nature. Gan (2014) defines economic uncertainty as uncertainty with regard to future economic events. Therefore, the prediction of a negative relationship between the resources available and the value attributed to more sustainable items defines a common point between the variables of this factor.

The variables involved in this factor, despite not having large loadings, seem to form barriers to sustainable public procurement in a relatively homogeneous way. Generally, the financial dimension of environmental management is the common aspect between the variables of this factor; not only the cost involved in acquiring sustainable items, such as in variables V1 and V7, but also a lack of financial resources directly (V4) or indirectly (V18) caused by the political cycle.

Although instability caused by the political cycle (V18) may seem to be unrelated to the financial dimension, it represents a potential sudden change in priorities, which can affect investment preferences, thereby making resources unavailable for certain areas. Similarly, the perception that sustainable procurement threatens or competes with other initiatives (V20) makes sense if one assumes that spending on public purchases is greater when it involves sustainable items, which is the basis of the composition of the group.

Table 10 shows the composition of Factor 4, whose variables have in common the belief that market aspects are barriers to public procurement. The term "market" is used as in Mosgaard et al. (2013), who use the term in a specific sense referring to a set of trade relations for a 


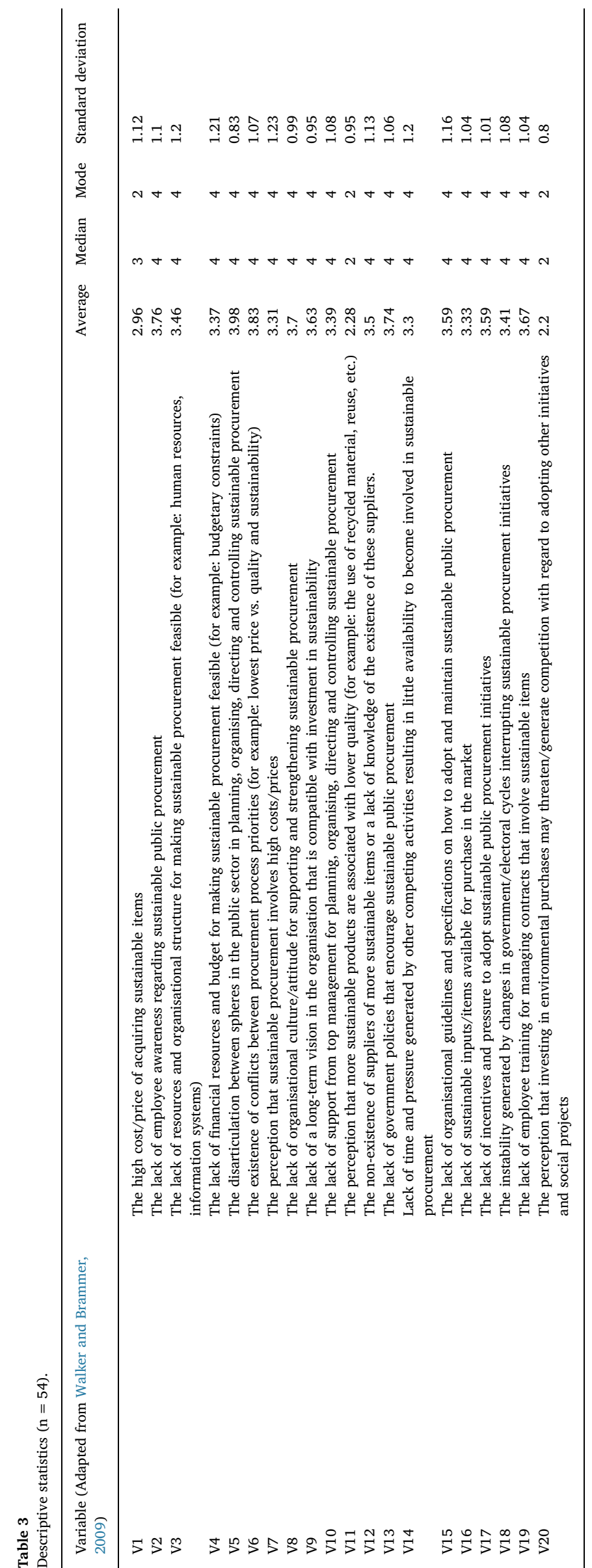

given type of product. Therefore, "Market Aspects" refers to the variables that have to do with the supply of products that are part of a set of particular trade relations, in this case those related to sustainable goods.

Factor 4 contains only 2 variables, which refer to the non-existence (or ignorance of the existence) of suppliers of more sustainable items (V12) and the lack of sustainable inputs and items available for purchase in the market (V16). Both variables relate specifically to concerns regarding the availability of sustainable items in the market.

Table 11 shows the variables that make up Factor 5 . The common characteristic of the variables in this group is that they act as barriers to the implementation of initiatives in sustainable public procurement. The two variables cited present problems that are faced by procurement sector employees in the tangible and operational dimensions of sustainable procurement management. While the first deals with the lack of time professionals have for involvement in sustainable public procurement, the second variable deals specifically with the lack of training for managing contracts involving sustainability in public procurement.

\subsection{Kruskal-Wallis test}

The Kruskal-Wallis Test yielded significant results $(\mathrm{p}>0.05)$ for some of the control variables described in Table 2, which organises the differences observed according to the following control variables:

- org 1 - Respondents from sub-national organisations view lack of support from senior management (V10) as more of a barrier to sustainable public procurement (3.677) than respondents from federal organisations (3) do.

- org 1 - Federal organisations see shortcomings in attitude and organisational culture (V8) to be less of a barrier to sustainable public procurement (3.435) than sub-national organisations do (3.903).

- pos 1 - Respondents in operational-level positions see the perception that sustainable procurement implies a high cost/price (V7) as a more significant barrier (3.607) to sustainable procurement than planning-level employees do (3.316).

- pos 1 - The significance of the variable V20 is $<0.05$. Professionals in planning positions perceive that competition for investment in with other social initiatives and projects (V20) is a greater barrier to sustainable public procurement (2.632) than professionals in operational positions do (2.036).

\section{Discussion: implications for theory and practice}

The two variables that respondents most agreed were barriers to sustainable public procurement-V5 and V6-fell within the same factor: "Aspects of Organisational Culture".

Although the disarticulation between public sector spheres in planning, organising, directing and controlling sustainable purchases (V5) and the existence of conflicts between purchasing process priorities (V6) are not correlated, both variables correlate with the lack of attitude and organisational culture for supporting and strengthening sustainable purchasing (V8), which indicates the potential transversal character of the V8 barrier.

The literature offers a perspective on the above analysis into the relationship between variables V5, V6 and V8. Jabbour et al. (2014) suggest that implementing major environmental programmes in Brazil can be a challenge, as it requires the involvement of both resources and related change management efforts. The work of Preuss and Walker (2011) supports the argument that organisational culture influences the willingness of employees to engage in sustainable public procurement, which is a prerequisite for substantial change.

Therefore, shortcomings in attitudes and organisational culture (V8) will improve to the extent that leaders or senior management attribute greater significance to sustainability-related actions and minimise the 


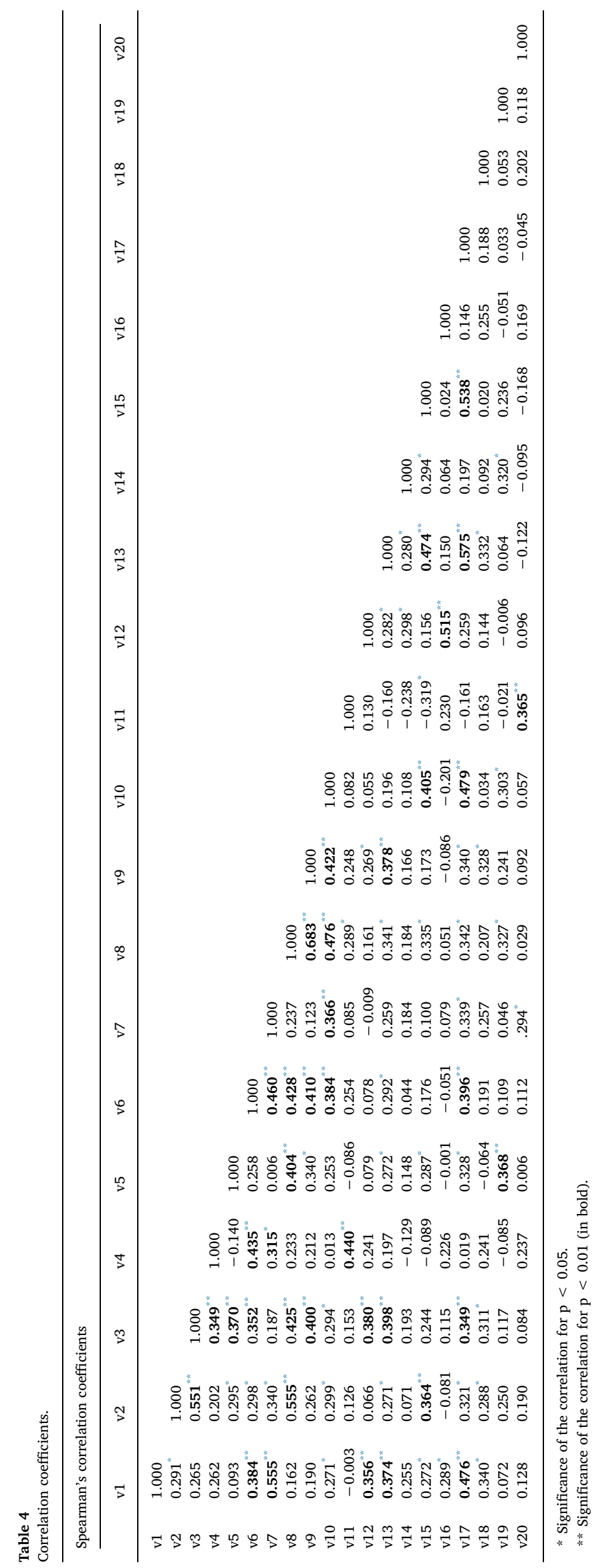


Table 5

Commonality of the variables.

\begin{tabular}{llllllll}
\hline \multicolumn{7}{l}{ Variables - Commonalities } \\
\hline v1 & 0.694 & v6 & 0.53 & v11 & 0.713 & v16 & 0.753 \\
v2 & 0.519 & v7 & 0.815 & $\mathbf{v 1 2}$ & 0.747 & $\mathbf{v 1 7}$ & 0.646 \\
v3 & 0.609 & v8 & 0.719 & $\mathbf{v 1 3}$ & 0.597 & $\mathbf{v 1 8}$ & 0.362 \\
v4 & 0.646 & v9 & 0.688 & $\mathbf{v 1 4}$ & 0.576 & $\mathbf{v 1 9}$ & 0.777 \\
v5 & 0.562 & v10 & 0.599 & $\mathbf{v 1 5}$ & 0.617 & $\mathbf{v 2 0}$ & 0.617 \\
\hline
\end{tabular}

Table 6

Factors and loadings of the variables used in the research (relevant values in bold).

\begin{tabular}{llllll}
\hline Variable & Factor 1 & Factor 2 & Factor 3 & Factor 4 & Factor 5 \\
\hline V1 & 0.155 & 0.364 & $\mathbf{0 . 6 8 7}$ & 0.255 & -0.027 \\
V2 & $\mathbf{0 . 6 1}$ & 0.167 & 0.322 & -0.122 & -0.014 \\
V3 & $\mathbf{0 . 6 8 6}$ & 0.137 & 0.118 & 0.311 & -0.091 \\
V4 & 0.365 & -0.354 & $\mathbf{0 . 3 9 4}$ & 0.316 & -0.364 \\
V5 & $\mathbf{0 . 5 0 9}$ & 0.233 & -0.181 & 0.118 & 0.449 \\
V6 & $\mathbf{0 . 5 9 6}$ & -0.009 & 0.416 & 0.028 & 0.018 \\
V7 & 0.175 & 0.098 & $\mathbf{0 . 8 6 9}$ & -0.139 & -0.003 \\
V8 & $\mathbf{0 . 7 9 7}$ & 0.057 & 0.166 & 0.026 & 0.229 \\
V9 & $\mathbf{0 . 8 0 6}$ & 0.012 & 0.049 & 0.096 & 0.163 \\
V10 & $\mathbf{0 . 6 0 5}$ & 0.24 & 0.23 & -0.3 & 0.181 \\
V11 & 0.408 & $-\mathbf{0 . 6 7}$ & 0.155 & 0.261 & -0.066 \\
V12 & 0.204 & 0.166 & 0.004 & $\mathbf{0 . 8 2 2}$ & 0.032 \\
V13 & 0.343 & $\mathbf{0 . 5 9 7}$ & 0.16 & 0.291 & -0.114 \\
V14 & -0.01 & 0.49 & 0.12 & 0.252 & $\mathbf{0 . 5 0 8}$ \\
V15 & 0.239 & $\mathbf{0 . 7 1 9}$ & 0.041 & -0.001 & 0.205 \\
V16 & -0.142 & -0.051 & 0.205 & $\mathbf{0 . 8 2 7}$ & 0.07 \\
V17 & 0.381 & $\mathbf{0 . 6 5 3}$ & 0.241 & 0.127 & 0.008 \\
V18 & 0.215 & -0.04 & $\mathbf{0 . 5 0 6}$ & 0.24 & -0.009 \\
V19 & 0.248 & 0.002 & 0.001 & -0.048 & $\mathbf{0 . 8 4 5}$ \\
V20 & 0.065 & -0.444 & $\mathbf{0 . 4 8 5}$ & 0.196 & 0.377 \\
\hline
\end{tabular}

existing perception of a disarticulation between public spheres (V5) and conflicts between priorities (V6).

Organisational culture, then, is a potential mediator between variables that relate to employees' perceptions of priorities and the actions of senior management. Shortcomings in attitude and organisational culture (V8) correlate with other variables related to culture or organisational structure, as well as to support from senior management, thus confirming the analysis. This is in line with the findings of Roman (2017), Islam et al. (2017), and Brammer and Walker (2011).

We strongly recommend that the Brazilian government invests more in initiatives such as their guidelines for implementing sustainable public procurement (MMA, 2016b). This kind of initiative could enhance awareness and skills that will unlock the full potential of the A3P programme. As affirmed by Oliveira and Santos (2015), if programmes to push forward sustainable procurement are not supported by training and development of public servants and suppliers, cultural challenges will remain, hampering important initiatives such as these.

In addition, both V9, "the lack of a long-term vision in the organisation that is compatible with investment in sustainability" and V2, "the lack of employee awareness regarding sustainable public procurement"
Table 8

Composition of Factor 2.

\begin{tabular}{|c|c|c|}
\hline \multicolumn{3}{|c|}{ Factor 2-Motivational aspects } \\
\hline Variable & Barrier & Loading \\
\hline V11 & $\begin{array}{l}\text { The perception that more sustainable products are } \\
\text { associated with lower quality (for example: the use of } \\
\text { recycled material, reuse, etc.) }\end{array}$ & -0.670 \\
\hline V13 & $\begin{array}{l}\text { The lack of government policies that encourage sustainable } \\
\text { public procurement }\end{array}$ & 0.597 \\
\hline V15 & $\begin{array}{l}\text { The lack of organisational guidelines and specifications on } \\
\text { how to adopt and maintain sustainable public procurement }\end{array}$ & 0.719 \\
\hline V17 & $\begin{array}{l}\text { The lack of incentives and pressure to adopt sustainable } \\
\text { public procurement initiatives }\end{array}$ & 0.653 \\
\hline
\end{tabular}

Table 9

Composition of Factor 3.

\begin{tabular}{llc}
\multicolumn{2}{l}{ Factor $3-$ Aspects of Economic Uncertainty } & \\
\hline Variable & Barrier & Loading \\
\hline V1 & $\begin{array}{l}\text { The high cost/price of acquiring sustainable items } \\
\text { V4 }\end{array}$ & 0.687 \\
& $\begin{array}{l}\text { The lack of financial resources and budget for making } \\
\text { sustainable procurement feasible (for example: budgetary } \\
\text { constraints) }\end{array}$ & 0.394 \\
V7 & $\begin{array}{l}\text { The perception that sustainable procurement involves high } \\
\text { costs/prices }\end{array}$ & 0.869 \\
V18 & $\begin{array}{l}\text { The instability generated by changes in government/ } \\
\text { electoral cycles interrupting sustainable procurement }\end{array}$ & 0.506 \\
& $\begin{array}{l}\text { initiatives } \\
\text { The perception that investing in environmental purchases } \\
\text { V20 }\end{array}$ & 0.485 \\
& $\begin{array}{l}\text { may threaten/generate competition with regard to adopting } \\
\text { other initiatives and social projects }\end{array}$ &
\end{tabular}

Table 10

Composition of Factor 4

\begin{tabular}{|c|c|c|}
\hline \multicolumn{3}{|c|}{ Factor 4 - Market Aspects } \\
\hline Variable & Barrier & Loading \\
\hline V12 & $\begin{array}{l}\text { The non-existence of suppliers of more sustainable items or } \\
\text { a lack of knowledge of the existence of these suppliers. }\end{array}$ & 0.822 \\
\hline V16 & $\begin{array}{l}\text { The lack of sustainable inputs/items available for purchase } \\
\text { in the market }\end{array}$ & 0.27 \\
\hline
\end{tabular}

correlate with V8, underlining its transversal character, and providing cohesion to the Aspects of Organisational Culture factor. However, this analysis points to the need for specific studies on cultural barriers to sustainable public procurement, as Witjes and Lozano (2016) have already noted.

The Motivational Aspects category shows a negative loading of the variable concerning the perception that more sustainable products are associated with poorer quality (V11). This variable relates to Kaufman's (2014) observations on certain groups stigmatising sustainable products

Table 7

Composition of Factor 1.

\begin{tabular}{|c|c|c|}
\hline Variable & Barrier & Loading \\
\hline V2 & The lack of employee awareness regarding sustainable public procurement & 0.610 \\
\hline V3 & The lack of resources and organisational structure for making sustainable procurement feasible (for example: human resources, information systems) & 0.686 \\
\hline V5 & The disarticulation between spheres in the public sector in planning, organising, directing and controlling sustainable procurement & 0.509 \\
\hline V6 & The existence of conflicts between procurement process priorities (for example: lowest price vs. quality and sustainability) & 0.596 \\
\hline V8 & The lack of organisational culture/attitude for supporting and strengthening sustainable procurement & 0.797 \\
\hline V9 & The lack of a long-term vision in the organisation that is compatible with investment in sustainability & 0.806 \\
\hline V10 & The lack of support from top management for planning, organising, directing and controlling sustainable procurement & 0.605 \\
\hline
\end{tabular}


Table 11

Composition of Factor 5.

\begin{tabular}{llc}
\hline \multicolumn{2}{l}{ Factor 5 - Operational Aspects } & Loading \\
\hline Variable & Barrier & 0.508 \\
\hline V14 & $\begin{array}{l}\text { Lack of time and pressure generated by other competing } \\
\text { activities resulting in little availability to become involved } \\
\text { in sustainable procurement } \\
\text { The lack of employee training for managing contracts that } \\
\text { V19 }\end{array}$ & 0.845 \\
\hline
\end{tabular}

as inferior. The negative correlation of this variable within this factor group implies that the greater the barrier caused by the association of sustainable products with poorer quality (V11), the less it is perceived that other motivational issues constitute a barrier.

Generally, the perception that more sustainable products are associated with poorer quality (V11) correlates with two of the variables dealing with economic uncertainty; specifically, the perception that investment in environmental purchases can compete with the adoption of other initiatives (V20) and the lack of financial resources and budget for making sustainable purchases feasible (V4). This relationship between the variables may suggest that the more respondents perceive sustainable items as being of inferior quality, the greater is the perception that such purchases lead to a loss of efficiency in the deployment of limited public resources.

This research does not confirm that procurement costs and budget constraints are critical barriers to the advancement of sustainable public procurement initiatives (Zhu et al., 2013; Brammer and Walker, 2011; Walker and Brammer, 2009). One possible explanation is that the companies studied are already aligned with the government guidelines for A3P, which implies that organisations operating in an environment governed by ecological modernisation principles are able to reconcile economic and environmental development.

The Kruskal-Wallis tests conducted indicate differences in the views held by respondents related to the type of organisation to which they belong and to the type of role held. In general, respondents from federal agencies see fewer problems with regard to organisational culture and senior management support. One possible explanation for this result is that, since federal agencies are closer to senior management, communication is easier, which favours them when it comes to dealing with any lack of support. In fact, federal agencies may actually receive more support, leading them to perceive this variable as less of a barrier. This result may be explained by Oliveira and Santos (2015), who suggest that sustainable procurement across Brazil has been influenced by the federal level. Consequently, public bodies at the federal level may have more experience in dealing with sustainability management, implying fewer difficulties in dealing with programmes such as A3P.

Professionals involved in planning activities tend to perceive the cost of sustainable items as less of a barrier, while more frequently perceiving the competition that exists between the acquisition of sustainable items and other activities as a barrier. This may be explained by the fact that planning professionals are concerned with the availability of resources. As a result, they may have greater knowledge of or access to resources than the occupants of operational positions. This result is consistent with the study by Lodgaard et al. (2016), which presented results in which workers-unlike senior management-tended to attribute the reasons for success to the commitment of senior management, rather than to the tools and methods that were implemented.

\section{Conclusions}

The main findings of this article suggest that: (i) cultural factors constitute a significant barrier to sustainable public purchasing; (ii) the perception of disarticulation between public sector spheres in the planning, organisation, direction, and control of sustainable purchases is also a barrier. These results relate specifically to the Brazilian context of sustainable public purchasing. For example, Oliveira and Santos (2015) affirm that, in Brazil, the pertinent laws come both from the federal sphere and from state/local authorities. Of course, co-ordination should be put in place. Additionally, programmes such as A3P may not achieve success without a clear understanding of the various aspects of sustainability management in the public sector, nor without the necessary and continuous alertness to developments in the field (Oliveira and Santos, 2015).

The main implications of this research suggest a potential future focus for both practitioners and researchers. Studies on the cultural dimensions of sustainable public procurement are needed to address such challenges, exploit its potential and mitigate its negative effects. For policymakers aiming to develop this field, institutional changes must be implemented in observation of cultural values and relations. For Brazilian sustainability policymakers in particular, based both on the results of this research and on the previous literature (Oliveira and Santos, 2015), this will involve:

- Developing extensive training on sustainability management in the public sector;

- Conducting workshops and meetings with representatives from other countries in Latin America to share knowledge on sustainable public procurement;

- Coordinating efforts towards clear targets and ambitions regarding sustainable procurement, in order to build up cultural bonds among a variety of public sector bodies.

The existing literature on the subject of barriers to sustainable public procurement highlights that: (i) acquisition costs and budget constraints have been indicated as critical barriers to the advancement of sustainable public procurement initiatives (Zhu et al., 2013; Brammer and Walker, 2011; Walker and Brammer, 2009), and that (ii) support, attitude, organisational culture, and leadership styles are also factors which have hindered sustainable public procurement (Roman, 2017; Islam et al., 2017; Brammer and Walker, 2011). This research did not confirm item (i), but did confirm item (ii).

One possible explanation for the non-confirmation of item (i) is that the companies studied are already aligned with the government's A3P guidelines, implying that organisations operating in an environment governed by the principles of ecological modernisation are able to reconcile economic and environmental development. Another possible explanation would reside in the duality of behaviour from organisational and individual consumers (Foxall et al., 2006). In one case study research at least in Brazil, the same individual would consider costs as a barrier for individual sustainable purchases but not for organisational sustainable purchases in most cases (Couto and Coelho, 2015). This result indicates an important theoretical contribution of this research, relating the subject of sustainable public procurement to the Theory of Ecological Modernisation.

Variable 8, "the lack of organisational culture/attitude for supporting and strengthening sustainable procurement", proved key to understanding the main barriers detected by this research: disarticulation between public sector spheres in planning, organising, directing and controlling sustainable procurement (V5), and the existence of conflicts between priorities in the purchasing process (V6). In this sense, organisational culture presents a potential mediating factor between variables related to employees' perceptions of the priorities and actions of top management.

We believe that this research has successfully addressed the gap it proposed to address, and that it has additionally offered a new state-ofthe-art view by indicating the main barriers to sustainable public procurement, particularly in the Brazilian context, analysed according to variables already validated by the literature. The practical implication for public administration professionals is the need to develop 
sustainable procurement management tools that involve better co-ordination of public spheres and intervention in organisational culture based on the actions of senior management.

In the Brazilian context, it is particularly relevant to strength the need for institutional training, aligned with sustainability target-setting for public expenditures, and coordination of efforts among Federal, State and local (county) public institutions, in order to foster cultural changes towards sustainable purchasing, as evidenced in this research for three main reasons. First, Brazil is a continental country with autonomous public institutions at the Federal, State and County levels, with their own budgets and autonomy for decision-making. Second, important public expenditures such as health and education are financially executed, implemented and supervised autonomously at the local level. Third, there are some scant but non anecdotal evidences from previous research on a potentially meagre compliance with existing regulations. For example in a random sample of 12 Federal Government Ministries (Alencastro et al., 2014), three federal universities (Aragão and Jabbour, 2017), and at the National Institute of Geography and Statistics nationwide (Couto and Coelho, 2015). It is worth mentioning that the relevance of these findings for the Brazilian context is consistent with results from a Delphi panel of Brazilian experts on sustainable public procurement in Brazil, conducted by Couto and Ribeiro (2016).

Among the limitations of this study we can point out the relatively low number of respondents for factor analysis. As a result, and related to the large number of variables involved, some variables yielded low commonality values. Moreover, the heterogeneity of the respondents also prevented further analyses on possible response patterns related to the time taken by respondents to return the questionnaire, as well as patterns related to other characteristics. We also note that organisational theories other than Ecological Modernisation Theory could have been adopted to understand the full complexity of sustainable procurement in the public sector. We strongly recommend future researchers to use, for example, stakeholders' theory and the resourcebased view to develop this discussion further (Sarkis et al., 2011). Finally, the Brazilian economic and legal contexts as portrayed by Oliveira and Santos (2015) should be further applied to understand the possibilities and limitations of sustainable public purchasing.

\section{References}

Agarchand, N., Laishram, B., 2017. Sustainable infrastructure development challenges through PPP procurement process: Indian perspective. Int. J. Managing Projects Bus. 10 (3), 642-662. http://dx.doi.org/10.1108/IJMPB-10-2016-0078.

Ageron, B., Gunasekaran, A., Spalanzani, A., 2012. Sustainable supply management: an empirical study. Int. J. Prod. Econ. 140 (1), 168-182. http://dx.doi.org/10.1016/j. ijpe.2011.04.007.

Alencastro, M.A.C., da Silva, E.V., Lopes, A.M.D., 2014. Sustainable procurements in the Brazilian public administration: The federal Executive Power's experience [Contratações sustentáveis na administração pública brasileira: A experiência do Poder Executivo federal]. Revista de Administracao Publica 48 (1), 207-235. http:// dx.doi.org/10.1590/S0034-76122014000100009.

Aragão, C.G., Jabbour, C.J.C., 2017. Green training for sustainable procurement? Insights from the Brazilian public sector. Ind. Commer. Train. 49 (1), 48-54. http://dx.doi. org/10.1108/ICT-07-2016-0043.

Bhadauria, V.S., Toms, L., Green, K.W., Meacham, J., 2014. Do green information systems impact performance? Int. J. Prod. Qual. Manage. 13 (4), 377-394.

Brammer, S., Walker, H., 2011. Sustainable procurement in the public sector: an international comparative study. Int. J. Oper. Prod. Manage. 31 (4), 452-476. http://dx doi.org/10.1108/01443571111119551.

Chu, S.H., Yang, H., Lee, M., Park, S., 2017. The impact of institutional pressures on green supply chain management and firm performance: top management roles and social capital. Sustainability 9 (5), 764. http://dx.doi.org/10.3390/su9050764.

Couto, H.L.G., Coelho, C., 2015. Critical factors in the behavior of public managers responsible for sustainable procurement: Differences between organizational and individual consumption [Fatores críticos no comportamento do gestor público responsável por compras sustentáveis: Diferenças entre consumo individual e organizacional]. Revista de Administracao Publica 49 (2), 519-543. http://dx.doi.org/10. 1590/0034-7612113443.

Couto, H.L.G., Ribeiro, F.L., 2016. Objectives and challenges of the sustainable public procurement policy in Brazil: Expert opinions [Objetivos e desafios da política de compras públicas sustentáveis no Brasil: A opinião dos especialistas]. Revista de Administracao Publica 50 (2), 331-343. http://dx.doi.org/10.1590/0034-
7612146561

Dawson, G.F., Probert, E.J., 2007. A sustainable product needing a sustainable procurement commitment: the case of green waste in Wales. Sustain. Dev. 15 (2), 69-82. http://dx.doi.org/10.1002/sd.307.

De Winter, J.C.F., Dodou, D., Wieringa, P.A., 2009. Exploratory factor analysis with small sample sizes. Multivariate Behav. Res. 44, 147-181. http://dx.doi.org/10.1080/ 00273170902794206.

Dillman, D., 1991. The design and administration of mail surveys. Annu. Rev. Soc. 17 (1), 225-249. http://dx.doi.org/10.1146/annurev.so.17.080191.001301.

Dubey, R., Gunasekaran, A., Childe, S.J., Papadopoulos, T., Wamba, S.F., Song, M., 2016. Towards a theory of sustainable consumption and production: constructs and measurement. Resour. Conserv. Recycl. 106, 78-89. http://dx.doi.org/10.1016/j. resconrec. 2015.11.008.

Dubey, R., Gunasekaran, A., Childe, S.J., Papadopoulos, T., Hazen, B., Giannakis, M., Roubaud, D., 2017. Examining the effect of external pressures and organizational culture on shaping performance measurement systems (PMS) for sustainability benchmarking: some empirical findings. Int. J. Prod. Econ. 193, 63-76. http://dx.doi. org/10.1016/j.ijpe.2017.06.029.

Fahimnia, B., Sarkis, J., Davarzani, H., 2015. Green supply chain management: a review and bibliometric analysis. Int. J. Prod. Econ. 162, 101-114.

Ferrer, A.L.C., Thomé, A.M.T., Scavarda, A., 2018. Sustainable urban infrastructure: a review, resources. Conserv. Recycl. 128, 360-372.

Foxall, G.R., Castro, J.O., James, V.K., Yani-de-Soriano, M.M., Sigurdsson, V., 2006. Consumer behavior analysis and social marketing: the case of environmental conservation. Behav. Soc. Issues 15 (1), 101-124.

Frohlich, M., 2002. Techniques for improving response rates in OM survey research. J. Oper. Manage. 20 (1), 53-62.

Gan, P.T., 2014. The optimal economic uncertainty index: a grid search application. Comput. Econ. 43 (2), 159-182. http://dx.doi.org/10.1007/s10614-013-9366-y.

Gunasekaran, A., Irani, Z., 2014. Sustainable Operations Management: design, modelling and analysis. J. Oper. Res. Soc. 65 (6), 801-805. http://dx.doi.org/10.1057/jors. 2014.26 .

Gunasekaran, A., McGaughey, R.E., Ngai, E.W., Rai, B.K., 2009. E-procurement adoption in the southcoast SMEs. Int. J. Prod. Econ. 122 (1), 161-175. http://dx.doi.org/10. 1016/j.ijpe.2009.05.013.

Hair, J.F., Black Anderson, R.E., Tatham, R.L., 2005. Analise Multivariada de Dados. Bookman 593

Ho, L.W., Dickinson, N.M., Chan, G., 2010. Green procurement in the Asian public sector and the Hong Kong private sector. Nat. Resour. Forum 34 (February (1)), 24-38.

Hoddinott, S.N., Bass, M.J., 1986. The Dillman total design survey method. Medecin De Famille Canadien 32, 2366-2368 PMCID: PMC2328022.

Hwang, Y., Kettinger, W.J., Yi, M.Y., 2013. A study on the motivational aspects of information management practice. Int. J. Inf. Manage. 33 (1), 177-184. http://dx.doi. org/10.1016/j.ijinfomgt.2012.09.002.

Islam, M.M., Murad, M.W., Mcmurray, A.J., Abalala, T.S., 2017. Aspects of sustainable procurement practices by public and private organisations in Saudi Arabia: an empirical study. Int. J. Sustain. Dev. World Ecol. 24 (4), 289-303. http://dx.doi.org/10. 1080/13504509.2016.1209794.

Jabbour, A.B., Jabbour, C.J., Sarkis, J., Govindan, K., 2014. Brazil's new national policy on solid waste: challenges and opportunities. Clean Technol. Environ. Policy 16 (1), 7-9. http://dx.doi.org/10.1007/s10098-013-0600-z.

Jin, M., Yu, A.J., 2015. Procurement auctions and supply chain performance. Int. J. Prod. Econ. 162, 192-200. http://dx.doi.org/10.1016/j.ijpe.2015.01.013.

Jung, S., Lee, S., 2011. Exploratory factor analysis for small samples. Behav. Res. Methods 43 (3), 701-709. http://dx.doi.org/10.3758/s13428-011-0077-9.

Kaufman, N., 2014. Overcoming the barriers to the market performance of green consumer goods. Resour. Energy Econ. 36, 487-507. http://dx.doi.org/10.1016/j. reseneeco.2013.05.007.

Kusi-Sarpong, S., Sarkis, J., 2017. Virtual Special Issue on sustainable supply chains and emerging economies: call for papers. Resour. Conserv. Recycl. A6-A7.

Kusi-Sarpong, S., Bai, C., Sarkis, J., Wang, X., 2015. Green supply chain practices evaluation in the mining industry using a joint rough sets and fuzzy TOPSIS methodology. Resour. Policy 46, 86-100. http://dx.doi.org/10.1016/j.resourpol.2014.10. 011.

Lau, K.H., 2011. Benchmarking green logistics performance with a composite index. Benchmarking Int. J. 18 (6), 873-896. http://dx.doi.org/10.1108/ 14635771111180743

Lodgaard, E., Ingvaldsen, J.A., Aschehouglnger, S., Gamme, I., 2016. Barriers to continuous improvement: perceptions of top managers, middle managers and workers. Procedia CIRP 41, 1119-1124. http://dx.doi.org/10.1016/j.procir.2016.01.012.

Luthra, S., Mangla, S.K., Xu, L., Diabat, A., 2016. Using AHP to evaluate barriers in adopting sustainable consumption and production initiatives in a supply chain. Int. J. Prod. Econ. 181, 342-349. http://dx.doi.org/10.1016/j.ijpe.2016.04.001.

MMA - Ministério do Meio Ambiente. Eixos Temáticos. (2016a). Available in: http:// www.mma.gov.br/responsabilidade-socioambiental/a3p/eixos-tematicos. (Accessed in: 28 ago. 2016).

MMA - Ministério do Meio Ambiente. Passo a passo para implantar a A3P. (2016b) Available in: http://www.mma.gov.br/legislacao/item/9167. (Accessed in: aug 28. 2016).

Malhotra, M., Grover, V., 1998. An assessment of survey research in POM: from constructs to theory. J. Oper. Manage. 16 (4), 407-425.

Mani, V., Gunasekaran, A., Papadopoulos, T., Hazen, B., Dubey, R., 2016. Supply chain social sustainability for developing nations: evidence from India. Resour. Conserv. Recycl. 111, 42-52. http://dx.doi.org/10.1016/j.resconrec.2016.04.003.

Mashele, F., Chuchu, T., 2018. An empirical investigation into the relationship between sustainability and supply chain compliance within the south african public and the 
private sector. J. Bus. Retail Manage. Res. 12 (2), 121-132.

Mathivathanan, D., Kannan, D., Haq, A.N., 2018. Sustainable supply chain management practices in Indian automotive industry: a multi-stakeholder view. Resour. Conserv. Recycl. 128, 284-305. http://dx.doi.org/10.1016/j.resconrec.2017.01.003.

Mcmurray, A.J., Islam, M.M., Siwar, C., Fien, J., 2013. Sustainable procurement in Malaysian organisations: practices, barriers and opportunities. J. Purchasing Supply Manage. 20 (3), 195-207. http://dx.doi.org/10.1016/j.pursup.2014.02.005.

Mercado, G., Hjortsø, C.N., Kledal, P.R., 2016. Public procurement for school breakfasts in the Bolivian Altiplan: governance structures enabling smallholder inclusion. J. Rural Stud. 44, 63-76. http://dx.doi.org/10.1016/j.jrurstud.2016.01.004.

Miemczyk, J., Johnsen, T.E., Macquet, M., 2012. Sustainable purchasing and supply management: a structured literature review of definitions and measures at the dyad, chain and network levels. Supply Chain Manage. Int. J. 17 (5), 478-496. http://dx. doi.org/10.1108/13598541211258564.

Morgan, K., 2008. Greening the realm: sustainable food chains and the public plate. Reg. Stud. 42 (9), 1237-1250.

Mosgaard, M., Riisgaard, H., Huulgaard, R.D., 2013. Greening non-product-related procurement - when policy meets reality. J. Clean. Prod. 39, 137-145. http://dx.doi. org/10.1016/j.jclepro.2012.08.018.

Mulaik, S.A., 1987. A brief history of the philosophical foundations of exploratory factor analysis. Multivariate Behav. Res. 22, 267-305. http://dx.doi.org/10.1207/ s15327906mbr2203_3.

Nijaki, L.K., Worrel, G., 2012. Procurement for sustainable local economic development. Int. J. Public Sector Manage. 25 (2), 133-153. http://dx.doi.org/10.1108/ 09513551211223785.

Oliveira, B.C.S.C.M., Santos, L.M.L., 2015. Compras públicas como política para o desenvolvimento sustentável. Revista de Administração Pública 49 (1), 189-206. http://dx.doi.org/10.1207/s15327906mbr2203_3.

Oruezabala, G., Rico, J.C., 2012. The impact of sustainable public procurement on sup plier management - the case of French public hospitals. Ind. Mark. Manage. 41 (4), 573-580. http://dx.doi.org/10.1016/j.indmarman.2012.04.004.

Palm, J., Backman, F., 2017. Public procurement of electric vehicles as a way to support a market: examples from sweden. Int. J. Electr. Hybrid Veh. 9 (3), 253-268. http://dx. doi.org/10.1504/IJEHV.2017.087587.

Panayiotou, N.A., Gayialis, S.P., Tatsiopoulos, I.P., 2004. An e-procurement system for governmental purchasing. Int. J. Prod. Econ. 90 (1), 79-102. http://dx.doi.org/10 1016/S0925-5273(03)00103-8.

Preuss, L., Walker, H., 2011. Psychological barriers in the road to sustainable development: evidence from public sector procurement. Public Adm. 89 (2), 493-521. http://dx.doi.org/10.1111/j.1467-9299.2010.01893.x.

Preuss, L., 2007. Buying into our future: sustainability initiatives in local government procurement. Bus. Strategy Environ. 16 (5), 354-365. http://dx.doi.org/10.1002/ bse. 578 .

Preuss, L., 2009. Addressing sustainable development through public procurement: the case of local government. Supply Chain Manage. Int. J. 14 (3), 213-223. http://dx. doi.org/10.1108/13598540910954557.

Ramayah, T., Lee, J.W.C., Mohamad, O., 2010. Green product purchase intention: some insights from a developing country. Resourc. Conserv. Recycl. 54 (12), 1419-1427. http://dx.doi.org/10.1016/j.resconrec.2010.06.007.

Roman, A.V., 2017. Institutionalising sustainability: a structural equation model of sustainable procurement in US public agencies. J. Clean. Prod. 143, 1048-1059. http:// dx.doi.org/10.1016/j.jclepro.2016.12.014.

Ruxton, G.D., Beauchamp, G., 2008. Some suggestions about appropriate use of the
Kruskal-Wallis test. Anim. Behav. 76 (3), 1083-1087. http://dx.doi.org/10.1016/j. anbehav.2008.04.011.

Sangle, S., 2010. Critical success factors for corporate social responsibility: a public sector perspective. Corporate Soc. Responsibility Environ. Manage. 17 (4), 205-214. http:// dx.doi.org/10.1002/csr.200.

Sarkis, J., Zhu, Q., Lai, K.H., 2011. An organisational theoretic review of green supply chain management literature. Int. J. Prod. Econ. 130 (1), 1-15. http://dx.doi.org/10. 1016/j.ijpe.2010.11.010.

Schein, E.H., 1983. The role of the founder in creating organisational culture. Organ. Dyn. 12 (1), 13-28. http://dx.doi.org/10.1016/0090-2616(83)90023-2.

Seuring, S., Müller, M., 2008. From a literature review to a conceptual framework for sustainable supply chain management. J. Clean. Prod. 16 (15), 1699-1710. http://dx. doi.org/10.1016/j.jclepro.2008.04.020.

Smart, P., Hemel, S., Lettice, F., Adams, R., Evans, S., 2017. Pre-paradigmatic status of industrial sustainability: a systematic review. Int. J. Oper. Prod. Manage. 37 (10), 1425-1450. http://dx.doi.org/10.1108/IJOPM-02-2016-0058.

Testa, F., Grappio, P., Gusmerotti, N.M., Iraldo, F., Frey, M., 2016. Examining green public procurement using content analysis: existing difficulties for procurers and useful recommendations. Environ. Dev. Sustain. 18 (1), 197-219. http://dx.doi.org/ 10.1007/s10668-015-9634-1.

Thomé, A.M.T., Scavarda, A., Ceryno, P., Remmen, A., 2016. Sustainable infrastructure: a review and a research agenda. J. Environ. Manage. 184, 143-156.

Thomson, J., Jackson, T., 2007. Sustainable procurement in practice: lessons from local government. J. Environ. Plann. Manage. 50 (3), 421-444. http://dx.doi.org/10. 1080/09640560701261695.

Walker, H., Brammer, S., 2009. Sustainable procurement in the United Kingdom public sector. Supply Chain Manage. Int. J. 14 (2), 128-137. http://dx.doi.org/10.1108/ 13598540910941993.

Walker, H., Brammer, S., 2012. The relationship between sustainable procurement and eprocurement in the public sector. Int. J. Prod. Econ. 140 (1), 256-268. http://dx.doi. org/10.1016/j.ijpe.2012.01.008.

Walker, H., Preuss, L., 2008. Fostering sustainability through sourcing from small businesses: public sector perspectives. J. Clean. Prod. 16 (15), 1600-1609. http://dx.doi. org/10.1016/j.jclepro.2008.04.014.

Walker, H., Miemczyk, J., Johnsen, T., Spencer, R., 2012. Sustainable procurement: past, present and future. J. Purchasing Supply Manage. 18 (4), 201-206. http://dx.doi. org/10.1016/j.pursup.2012.11.003.

Walker, H., Seuring, S., Sarkis, J., Klassen, R., 2014. Sustainable operations management: recent trends and future directions. Int. J. Oper. Prod. Manage. 34 (5). http://dx.doi. org/10.1108/IJOPM-12-2013-0557.

Witjes, S., Lozano, R., 2016. Towards a more Circular Economy: proposing a framework linking sustainable public procurement and sustainable business models. Resour. Conserv. Recycl. 112, 37-44.

Yee, W.H., Lo, C.W.H., Tang, S.Y., 2013. Assessing ecological modernization in China: stakeholder demands and corporate environmental management practices in Guangdong province. China Q. 213, 101-129.

Zhu, Q., Geng, Y., Sarkis, J., 2013. Motivating green public procurement in China: an individual level perspective. J. Environ. Manage. 126, 85-95. http://dx.doi.org/10. 1016/j.jenvman.2013.04.009.

Zhu, Q., Geng, Y., Sarkis, J., Lai, K.H., 2015. Barriers to promoting eco-Industrial parks development in China. J. Ind. Ecol. 19 (3), 457-467. http://dx.doi.org/10.1111/jiec. 12176. 